\title{
Effect of Plasma Surface Modification on Comfort Properties of Polyester/Cotton Blend Fabric
}

\author{
Baye Berhanu Yilma $^{a, b *}$, Joern Felix Luebben ${ }^{b}$ (D), Melkie Getnet Tadesse ${ }^{a}$ \\ ${ }^{a}$ Bahir Dar University, Ethiopian Institute of Textile and Fashion Technology (EiTEX), Bahir Dar, \\ Ethiopia \\ ${ }^{b}$ Albstadt-Sigmaringen University, Material and Process Engineering (MPE), 72458 Albstadt, Germany
}

Received: January 11, 2021; Revised: March 16, 2021; Accepted: March 21, 2021

In this study, vacuum oxygen plasma was applied to enhance the comfort properties of polyester/ cotton $(\mathrm{P} / \mathrm{C})$ blend fabric $(65 / 35 \%)$ for tropical climatic conditions. In addition, air and argon plasma were used to examine the aging effect by TEGEWA drop test. Taguchi method was employed to design the experiment and analyze the largest influential variable as well as optimal parameter levels. More attention was given to the evaluation of wickability, water vapour permeability/resistance, air permeability and surface characterization. Results revealed that all plasma treated comfort properties enhanced except air permeability of experimental runs at $1 \mathrm{O}_{2}$ and $7 \mathrm{O}_{2}$. Specifically, wickability of fabric increased at least by $43.25 \%$ and $37.63 \%$ in warp and weft directions, correspondingly, within 5 min of wicking time, whereas the thermal resistance reduced at least by $20.16 \%$. The SEM images depicted the formation of cracks, grooves, nanostructures and high degree of roughness on plasma treated surfaces.

Keywords: Plasma modification, wickability, comfort, polyester/cotton, skin model.

\section{Introduction}

In the textile industry, polyester/cotton $(\mathrm{P} / \mathrm{C})$ blend covers $58.45 \%$ of the world's market share ${ }^{1}$. The $\mathrm{P} / \mathrm{C}$ is the most common blend fabric and has been used extensively in apparel, home furnishing and other household applications. The main reason for this is due to its desired properties of user friendly, functional performance, aesthetic value, printability and affordability; more difficult to attain all these characteristics merely either in polyester (polyethylene terephthalate) or cotton fabric ${ }^{2,3}$. Specifically, the cotton fibre provides wear comfort due to the presence of hydroxyl groups in its cellulose structure that imparts hydrophilicity to the fibres which leads to the higher moisture absorption and wettability ${ }^{4}$. The polyester fibre also contributes to the blend fabric by offering high thermal stability, good strength, dimensional stability, good chemical resistance and acceptable easy-care properties ${ }^{5}$. However, the polyester fibre hinders the hydrophilic characteristics of the $\mathrm{P} / \mathrm{C}$ blend fabric; especially when the polyester proportion is higher than cotton ${ }^{6}$.

Regardless of the aforementioned excellent $\mathrm{P} / \mathrm{C}$ blend fabric properties, the hydrophobic surface of its polyester portion affects the comfort properties of the blend fabric when served for apparel purposes ${ }^{7}$. Particularly, the thermal comfort of the blend fabric depends on the abilities of heat and moisture vapour transmission as well as the absorption of the body sweats. The heat can be transferred through clothing by means of conduction, convection, radiation, and latent heat transfer by diffusion of water vapour and sweat (liquid). In

*e-mail: berhanu.baye9@gmail.com addition, the thermal insulation and evaporative resistance of clothing can regulate the exchange of heat between the body and the environment. In the case of the tropical climate and high level of physical activity, the sensible perspiration occurs in the form of liquid, namely sweat. Consequently, the skin is wet and feels discomfort ${ }^{8,9}$. Similarly, when wearing a garment made from $\mathrm{P} / \mathrm{C}$ blend fabric with a higher proportion of polyester, it tends to hold the perspiration in between the skin and the cloth due to the low water vapour absorbability of polyester compared to cotton ${ }^{10}$. Therefore, the $\mathrm{P} / \mathrm{C}$ blend fabric needs surface modification due to the presence of polyester fibre.

In this regard, several surface modification techniques have been applied on the fabric, aiming to the enhancement of its surface to be more hydrophilic. These methods include alkaline hydrolysis ${ }^{5}$, aminolysis ${ }^{11}$, applying natural biopolymer ${ }^{12}$, gas treatment ${ }^{13}$, silanization, UV treatment, flame treatment, and tethering molecules in bioconjugation ${ }^{14}$. However, the surface modification through wet chemical processes is non-specific, changing the bulk property, consuming high amounts of water and energy, and releases hazardous effluent to the environment ${ }^{15}$. In addition, flame and UV treatment affects the optical properties of the polymer ${ }^{14}$. To resolve these problems, cold plasma surface modification is an ideal option. Cold plasma can be made in a low pressure under vacuum or at atmospheric pressure in an open air, both of which are used for textile surface modification. Regarding the effectiveness of treatment, low pressure plasma is more preferred due to the high concentration of reactive species, the superior chemical selectivity, high controllability, the 
uniformity of a large surface area, and reproducibility of the results ${ }^{16,17}$.

Plasma is one of the states of matter and consists of a mixture of electrons, charged particles, neutral atoms and molecules ${ }^{13}$. The activated electrons and photons initiate the physical and chemical reactions through physical bombardment and plasma polymerization at the surface of the textile materials ${ }^{18}$. Plasma is a unique and gaseous treatment media for surface modification of textile substrate ${ }^{19}$. Compared with the classical chemical processes, plasma only modifies the outermost of the material surface layers by retaining its bulk property. In addition, it is cost effective and eco-friendly processes ${ }^{20}$. Due to the uniqueness of plasma, it has been widely used for surface modification of textile in order to impart the specific functional properties into the surface of the fabric ${ }^{16}$.

Recently, a few studies have been done by means of plasma surface modification to improve the comfort properties of certain textile fibres/fabrics. Particularly, some of the comfort properties of polyamide ${ }^{21}$, wool ${ }^{22}$, polyester ${ }^{23,24}$, bamboo viscose $\mathrm{e}^{25}$ and cotton ${ }^{26-28}$ fibres have been enhanced after plasma treatments. However, not only a few studies have been done to this topic but also the thermal comfort properties of $\mathrm{P} / \mathrm{C}$ blend fabric have not been investigated yet via plasma surface modification.

In this study, the effect of low pressure oxygen plasma treatment on thermal comfort properties of $\mathrm{P} / \mathrm{C}$ blend fabric, such as wickability, thermal resistance, air permeability, water vapour permeability and water vapour resistance were investigated. The Taguchi method was applied to design the experiment and analyze the data. In addition, the surface morphology and surface chemistry of the blend fabric were studied by using the surface characterization techniques.

\section{Experimental Methods}

\subsection{Materials}

The fabric sample used for this research is $65 \%$ polyester and $35 \%$ cotton blend fabric (Carrington textiles, UK) of plain weave ready to make shirt garment. The count of warp and weft yarn is $44 \mathrm{Ne}$. The fabric weight, thickness, warp and weft yarn densities are $115 \mathrm{~g} / \mathrm{m}^{2}, 0.22 \mathrm{~mm}, 144 \mathrm{EPI}$ and 72 PPI, respectively. The fabric samples were conditioned, before and after plasma treatment, according to ASTM D1776. The size of the sample depends on the dimension of the subsequent plasma effect measurement instruments. In this work, atmospheric air, oxygen and argon (Westfalen AG, Germany) gases were used for plasma surface modification. All gases were laboratory grade and used as received.

\subsection{Plasma Surface Modification}

The plasma surface modification was carried out by using a laboratory scale vacuum plasma reactor (Tetra 30 PC, Diener Electronic $\mathrm{GmbH}+\mathrm{Co} . \mathrm{KG}$, Germany). This plasma reactor consists of a rectangular vacuum chamber, approximately the volume of $34 \mathrm{~L}$, along with a movable sample holder over the ground electrode. The capacitive coupled low frequency (LF) power supply (frequency of $40 \mathrm{kHz}$ ) produced the total power up to $1000 \mathrm{~W}$ in a continuous or pulsed regime. The vacuum pump and suction from Leybold with the approx. volume of $80 \mathrm{~m}^{3} / \mathrm{h}$ also were the parts of the plasma reactor.

The samples were exposed to plasma surface modification using different combinations of plasma parameters. In the case of oxygen plasma treatment, the plasma process was designed and analyzed by employing the Taguchi method in order to investigate the thermal comfort properties of the blend fabric such as wickability, thermal resistance, air permeability, water vapour permeability and water vapour resistance. The experimental runs were set by using four factors and three levels, as presented in Table 1. On the other hand, in order to evaluate the aging effect through wettability, the blend fabric samples were treated using argon, air and oxygen plasmas, separately, at the condition of $500 \mathrm{~W}$, $30 \mathrm{~Pa}, 10 \mathrm{~min}$ and $1.0 \times 10^{-6} \mathrm{Nm}^{3} / \mathrm{s}$. All plasma processes were carried out under the base pressure of $0.5 \mathrm{~Pa}$ and the pump pressure of $20 \mathrm{~Pa}$ at room temperature. In addition, all plasma treatments were fully automated.

\subsection{Determination of water-vapour and thermal resistance or permeability}

The Permetest Skin Model (Sensora, Liberec, Czech Republic) was used to determine the relative water vapour permeability $\mathrm{P}_{\text {wv }}(\%)$, water vapour resistance $\mathrm{R}_{\text {et }}\left(\mathrm{m}^{2} \mathrm{~Pa} / \mathrm{W}\right)$ and thermal resistance $\mathrm{R}_{\mathrm{t}}\left(\mathrm{m}^{2} \mathrm{~K} / \mathrm{W}\right)$ of the blend fabrics. The measurement of the device was very similar to the ISO standard $11092^{29}$. This skin simulator consists of the measuring head, semi-permeable layer, heating elements, fan, temperature and relative humidity sensors. The working principles of the Permetest is given diagrammatically in Figure 1.

During the measurement of water vapour permeability and resistance, the measuring head was first masked with

Table 1. The experimental runs of oxygen $\left(\mathrm{O}_{2}\right)$ plasma with 4 factors and 3 levels.

\begin{tabular}{cccccc}
\hline Runs & Runs ID & Flow rate $\left(\mathbf{N m}^{3} / \mathbf{s}\right)$ & Pressure (Pa) & Power (W) & Time (min) \\
\hline 1 & $1 \mathrm{O}_{2}$ & $6.667 \times 10^{-7}$ & 20 & 600 & 5 \\
\hline 2 & $2 \mathrm{O}_{2}$ & $6.667 \times 10^{-7}$ & 40 & 700 & 10 \\
\hline 3 & $3 \mathrm{O}_{2}$ & $6.667 \times 10^{-7}$ & 50 & 800 & 20 \\
\hline 4 & $4 \mathrm{O}_{2}$ & $8.333 \times 10^{-7}$ & 20 & 700 & 5 \\
\hline 5 & $5 \mathrm{O}_{2}$ & $8.333 \times 10^{-7}$ & 40 & 600 & 10 \\
\hline 6 & $6 \mathrm{O}_{2}$ & $8.333 \times 10^{-7}$ & 50 & 800 & 10 \\
\hline 7 & $7 \mathrm{O}_{2}$ & $1 \times 10^{-6}$ & 20 & 600 & 20 \\
\hline 8 & $8 \mathrm{O}_{2}$ & $1 \times 10^{-6}$ & 40 & 700 & 5 \\
\hline 9 & $9 \mathrm{O}_{2}$ & $1 \times 10^{-6}$ & 50 & & \\
\hline
\end{tabular}




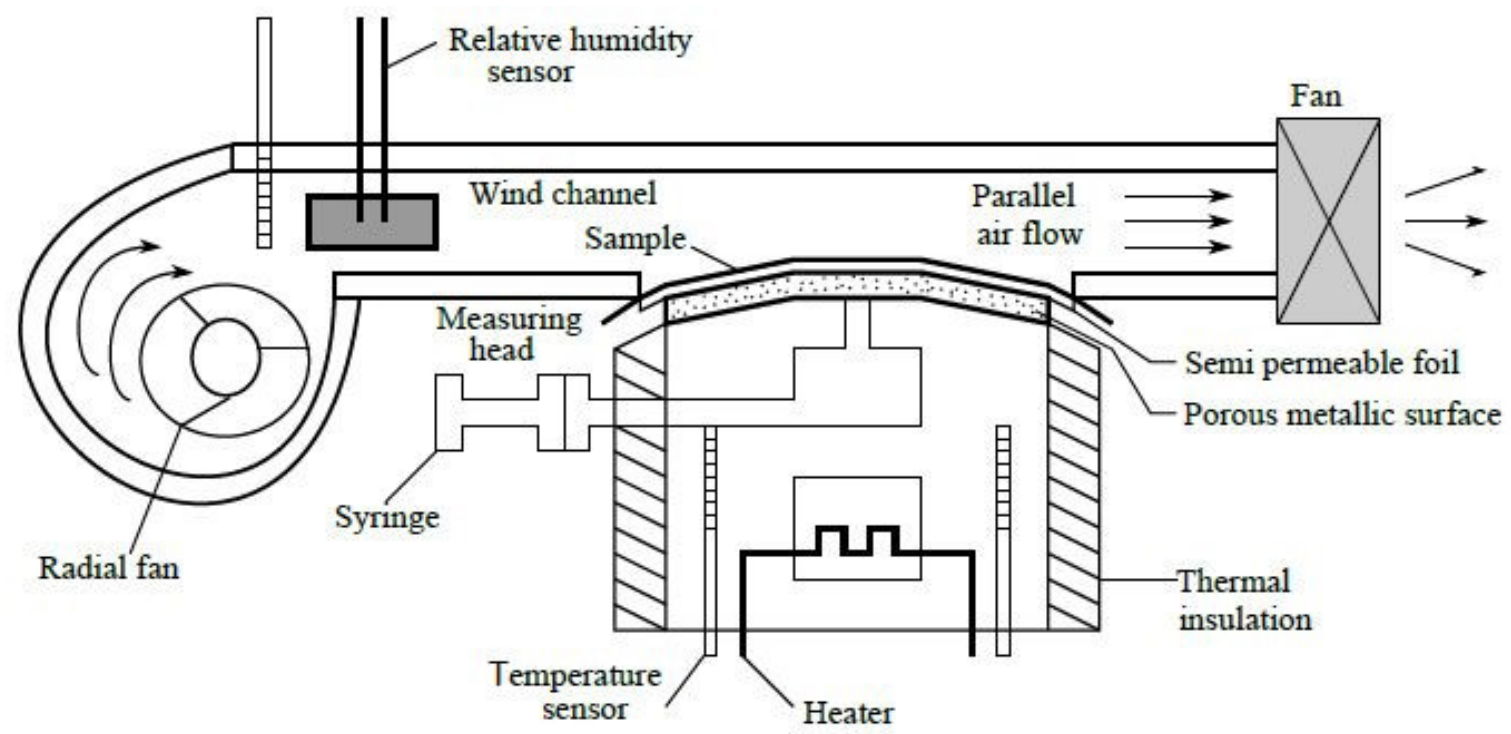

Figure 1. The working principle of Permetest, adapted from ${ }^{30}$.

semi-permeable foil to retain the measured garment to be dry. Then, $10 \mathrm{ml}$ of distilled water was inserted through a special orifice under the measuring head. A little curved metallic porous surface along with a semi-permeable foil layer was moistened and exposed in a wind channel to a parallel air flow with the velocity of $2 \mathrm{~m} / \mathrm{s}$. Special hydrophobic polypropylene reference fabric was used for calibration. The temperature of the measuring head also remained at room temperature for isothermal working conditions. The Permetest was used to measure the amount of heat loss when evaporation of water escaped from the porous measuring head surface without $\left(u_{o}\right)$ and with the fabric sample $\left(u_{s}\right)$, respectively. Both values were used to calculate the mean value and standard deviations. The sizes of the samples were $11 \mathrm{x} 11 \mathrm{~cm}^{2}$, but the measured area was $8 \mathrm{~cm}$ in diameter. The mean of six readings has been taken for relative water vapour permeability and water vapour resistance tests. At the time of testing, the outer layer of sample was exposed to the air flow and the opposite side also overlapped to the porous humid surface, which was used to simulate the underwear garments filled with the liquid sweat.

The relative water vapour permeability $\mathrm{P}_{w v}(\%)$ of the sample indicates the permeability of free measuring head surface and it can be calculated by using the following equation:

$P_{w v}(\%)=100 \times u_{s} / u_{o}$

The water vapour resistance $\mathrm{R}_{\mathrm{et}}\left(\mathrm{m}^{2} \mathrm{~Pa} / \mathrm{W}\right)$ can also be expressed in the following equation:

$R_{e t}=\left(P_{\text {wsat }}-P_{\text {wo }}\right)\left(1 / u_{s}-1 / u_{o}\right)=C(100-\varphi)\left(1 / u_{s}-1 / u_{o}\right)$

Where $\mathrm{P}_{\text {wat }}$ and $\mathrm{P}_{\text {wo }}$ are the values of water vapour saturation partial pressure in pascals, valid for ambient temperature, and the actual water vapour partial pressure in the laboratory, respectively. In addition, $\mathrm{C}$ is the value of the reference fabric for water vapour resistance (provided by the company as a standard) and $\varphi$ is the relative humidity.
The thermal resistance $\mathrm{R}_{\mathrm{t}}\left(\mathrm{mK} \cdot \mathrm{m}^{2} / \mathrm{W}\right)$ of the dry blend fabric was measured by the Permetest. The whole procedure followed similar to that of water vapour resistance measurement, except the measuring head was kept dry. The temperature of the measuring head was kept $10^{\circ} \mathrm{C}$ above the temperature of the air in the measuring channel. The thermal resistance $R_{t}$ has been worked out by the steady state electrical voltages with a fabric sample $\left(u_{s}\right)$ and without a fabric sample $\left(u_{o}\right)$ as well as by the sensitivity constant $\mathrm{K}\left(20.5 \mathrm{mK} . \mathrm{m}^{2} / \mathrm{W}\right)$. It can be determined by using the following equation:

$$
R_{t}=K\left(t_{H}-t_{o}\right)\left(1 / u_{s}-1 / u_{o}\right)
$$

Where $t_{H}$ and $t_{0}$ are the temperature of measuring head and the temperature of the laboratory air, respectively.

\subsection{Measurement of wickability}

The effect of oxygen plasma treatment on the wickability of $\mathrm{P} / \mathrm{C}$ blend fabric was evaluated by measuring the wicking height in the warp and weft directions according to DIN 53924. The samples size of $250 \times 30 \mathrm{~mm}^{2}$ were cut along the warp and weft directions. A strip sample was vertically suspended and $15 \mathrm{~mm}$ of its lower end was immersed inside a reservoir of distilled water with $1 \%$ reactive blue dye. The dye was used for tracking the movement of water against gravity on the strip. An average of three readings of the wicking height was taken for each sample from the clamped ruler after 5 min wicking time.

\subsection{Evaluation of water absorbency and aging effect}

TEGEWA drop test, similar to AATCC Test method 79, was used to determine the water absorbency of plasma treated and untreated $\mathrm{P} / \mathrm{C}$ blend fabric. A size of $150 \times 150 \mathrm{~mm}^{2}$ samples and $2 \mathrm{~g} / \mathrm{L}$ of patent blue $\mathrm{V}$ dye solution were prepared. The sample was tensioned horizontally on the tensioning device without contact underneath. Then, the glass funnel was placed on the sample to hold the drop pipette at a distance of $40 \mathrm{~mm}$. 
The amount of $0.05 \mathrm{~mL} \pm 10 \%$ solution was dropped from the pipette towards the sample once. The reading of sink-in time was started as soon as possible the drops landed on the sample. It was also stopped when the bright and the shiny surface of the drop disappeared. The diameter of the color spot was also measured when the sample was completely dried. In addition, the aging effect of air, argon and oxygen plasma treated samples were investigated by conditioning them for 1,7 and 14 days under standard conditions of $20 \pm 2{ }^{\circ} \mathrm{C}$ and $65 \pm 2 \% \mathrm{RH}$. The mean of the three readings was taken for each sample.

\subsection{Air Permeability}

The air permeability of plasma treated and untreated blend fabric samples were tested on SDLATLAS M021A air permeability tester at an air pressure of $100 \mathrm{~Pa}$ and $20 \mathrm{~cm}^{2}$ of test area, in the standard conditions of $20 \pm 2{ }^{\circ} \mathrm{C}$ and $65 \pm 2 \% \mathrm{RH}$, according to EN ISO 9237. The value of the air permeability was displayed in the pre-selected unit $\left(\mathrm{dm}^{3} / \mathrm{s} /\right.$ $\mathrm{m}^{2}$ ). An average of ten readings was taken for each sample.

\subsection{Surface characterization}

The $\mathrm{P} / \mathrm{C}$ blend fabric surface morphology was examined by Scanning Electron Microscopy SEM (FE-SEM: Zeiss Sigma VP, Germany) using secondary electrons. The samples were coated with 2-3 nm of gold for $12 \mathrm{~min}$ in the vacuum conditions before measurement in order to avoid charges on the surface. The analysis was done at the voltage of $5 \mathrm{kV}$ and the magnification of $10,000 \mathrm{X}$.

On the other hand, the surface chemistry of the blend fabric was studied by Attenuated Total Reflection Fourier Transform Infrared (ATR-FTIR) spectroscopies. ATR-FTIR analysis was carried out with Thermo Scientific iS10 FTIR spectrometer (Thermo Fisher Inc., USA) driven by the OMINIC $^{\mathrm{TM}}$ spectra $^{\mathrm{TM}}$ software to identify the functional groups found in the surface of plasma treated and untreated

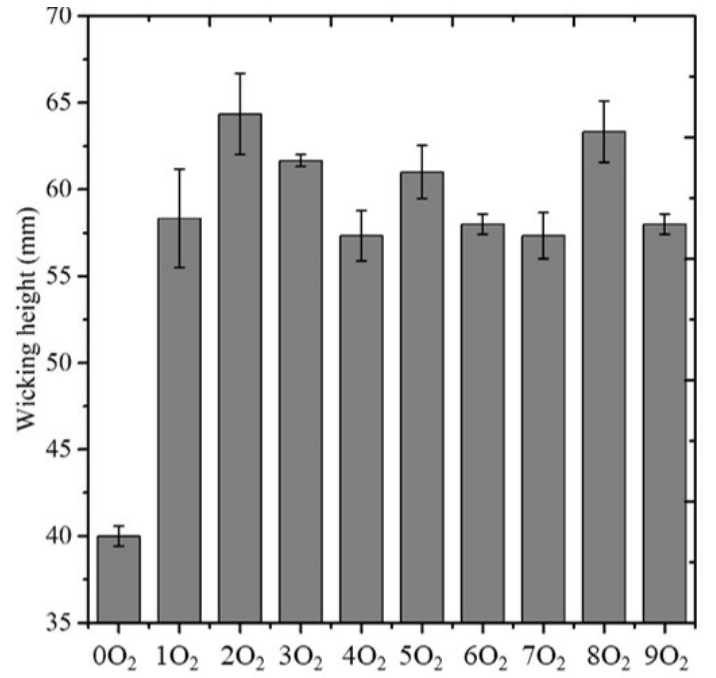

Experimental runs

(a) samples. It consists of a $\mathrm{KBr}$ beam splitter and a Deuterated Triglycine Sulfate (DTGS) detector. The spectra were found in the range of $650-4000 \mathrm{~cm}^{-1}$ wavenumber using 16 scans along with $4 \mathrm{~cm}^{-1}$ resolutions.

\subsection{Data analysis}

Experimental runs and optimization of oxygen plasma processes, for thermal comfort properties, were designed and analyzed by Taguchi method (Minitab software, version 18). Taguchi method is a special form of a statistical technique and mainly used by engineers and quality assurance professionals for process optimization and solving production problem $^{31}$. In addition, one-way-ANOVA was used to find the significance effect of oxygen plasma treatment on thermal comfort properties of $\mathrm{P} / \mathrm{C}$ blend fabric. If the $p$-value is less than 0.05 at $95 \%$ confidence interval, the plasma treatment has a significant effect on the thermal comfort properties of the blend fabric.

\section{Results and Discussion}

\subsection{Influence of oxygen plasma on wickability of fabrics}

Wickability (vertical wicking) of oxygen plasma treated and untreated $\mathrm{P} / \mathrm{C}$ blend fabrics are presented in Figure 2. By observing the bar graphs, it can be depicted that the wicking heights were raised in the range of 57.3 to $64.3 \mathrm{~mm}$ compared to $40 \mathrm{~mm}\left(0 \mathrm{O}_{2}\right)$ in the warp (Figure 2a) and 52.3 to $60 \mathrm{~mm}$ compared to $38 \mathrm{~mm}\left(0 \mathrm{O}_{2}\right)$ in the weft (Figure $2 \mathrm{~b}$ ) directions during 5 min wicking time. That means, wickability of treated fabrics increased by the range of 43.25 to $60.75 \%$ and 37.63 to $57.89 \%$ compared to untreated fabric in the warp and weft directions, respectively. In plasma treated and untreated $\mathrm{P} / \mathrm{C}$ blend fabrics, the wicking height in the warp was higher than that of weft directions due to the difference

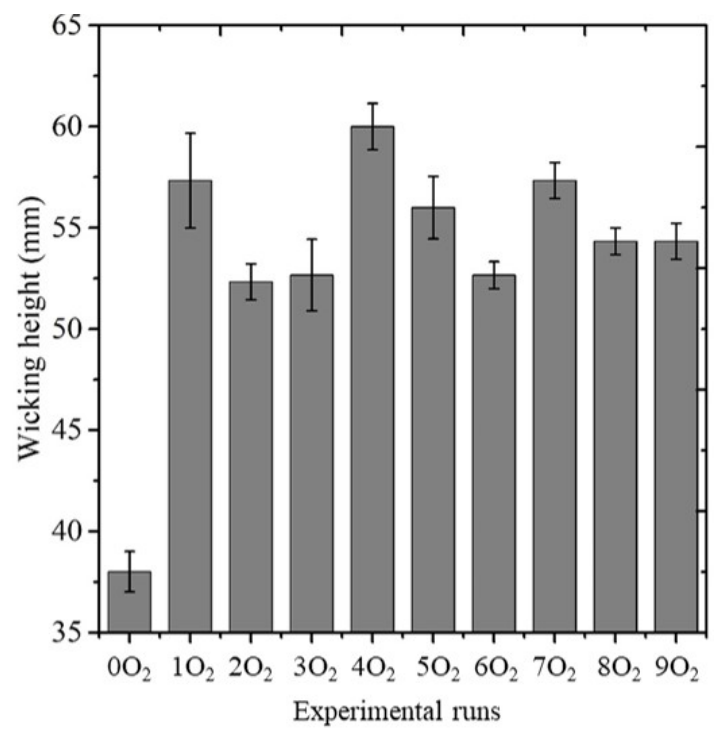

(b)

Figure 2. Effect of oxygen plasma on wickability of fabric in warp (a) and weft (b) directions. 
in yarn twist. This result depicts that types of fibre and yarn property can play a crucial role in wickability of the fabric.

Plasma etching altered the surface morphology of cotton and polyester fibres as shown in Figure $3 \mathrm{a}$ and $3 \mathrm{c}$. After plasma bombardment, the hydrophobic layer of polyester fibre modified and also hydrophilicity improved due to introduction of polar groups. In addition, cracks, roughness and nano-voids correspondingly developed on the surface of both fibres. These kinds of surface morphology can increase the capillary pressure of the liquid. In other words, the movement of liquid through the fabric governed by capillary force ${ }^{24}$. Therefore, oxygen plasma treatment can improve the wickability of $\mathrm{P} / \mathrm{C}$ blend fabric.

Optimization of the oxygen plasma process parameters for wickability of blend fabric was analyzed by Taguchi method. In this study, the plasma process primarily depends on flow rate, discharge power, operating pressure and exposure time, since other parameters are constant. As could be seen from Table 2, the discharge pressure has brought the largest influence on the wickability of the blend fabric both in warp and weft directions according to the delta values of $\mathrm{S} / \mathrm{N}$ ratios, by selecting the "Larger is better", from Minitab 18 software. The optimum parameter levels were also found at $6.667 \times 10^{-7} \mathrm{Nm}^{3} / \mathrm{s}, 40 \mathrm{~Pa}, 800 \mathrm{~W}$ and $20 \mathrm{~min}$ for the warp direction. Similarly, it occurred at $8.333 \times 10^{-7} \mathrm{Nm}^{3} / \mathrm{s}, 20 \mathrm{~Pa}$, $800 \mathrm{~W}$ and $5 \mathrm{~min}$ for the weft direction.

\subsection{Effect of plasma treatment on water-vapour permeability and resistance}

The bar graphs of water vapour permeability and water vapour resistance from oxygen plasma treated and untreated $\mathrm{P} / \mathrm{C}$ blend fabrics are shown in Figure 4 . The relative water vapour permeability $\mathrm{P}_{\mathrm{wv}}(\%)$ of plasma treated fabric increased in the range of 71.8 to $74.8 \%$ compared to $71.4 \%$ of untreated fabric. This improvement is most likely related to the formation of cracks and grooves over the surface of blend fabric. These developed cracks and grooves on the surface of fibres would reduce the capillary pressure and assist water vapour permeability ${ }^{25}$. On the other hand, water vapour resistance of plasma treated fabric decreased in the
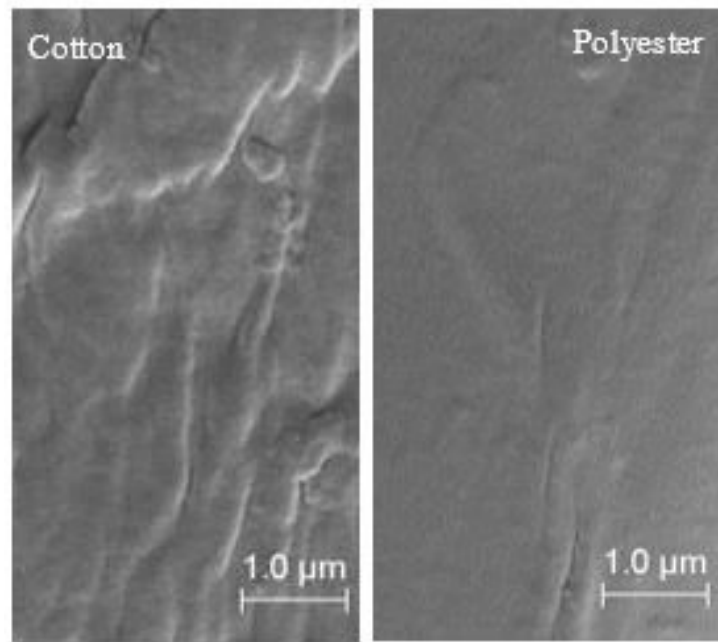

a)
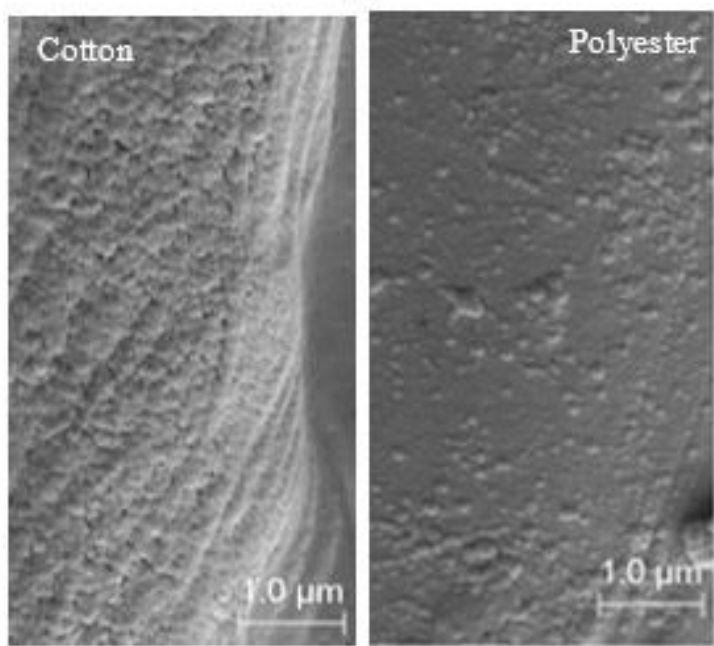

c)
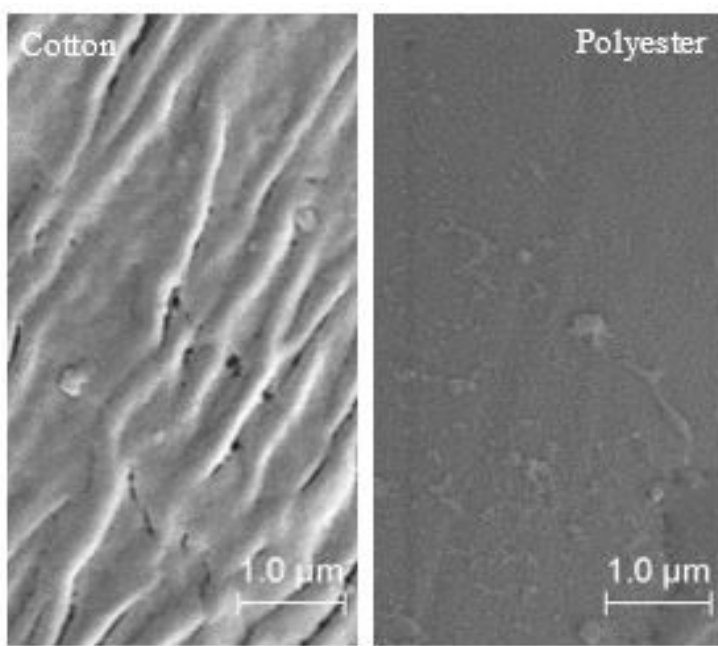

b)
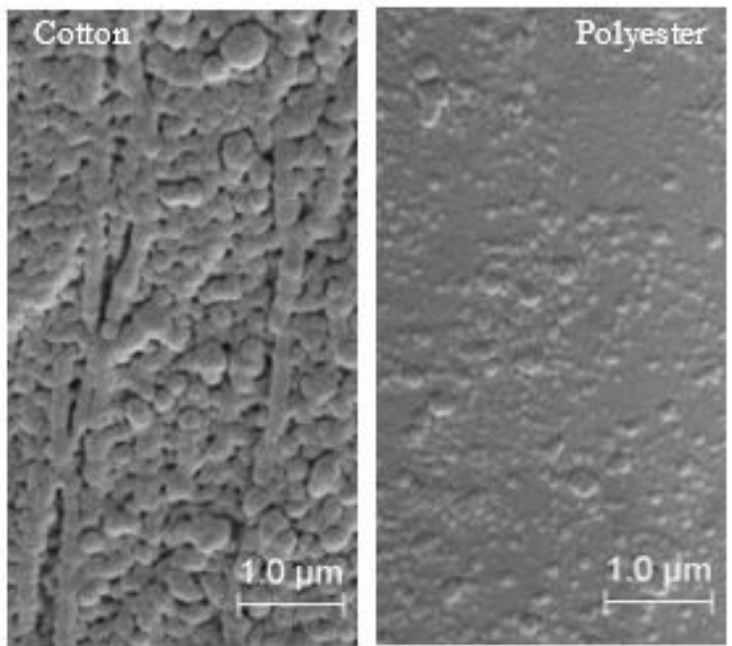

d)

Figure 3. SEM images of untreated (a), argon (b), oxygen (c) and air plasma (d) treated fibres. 
Table 2. Response table for mean of $\mathrm{S} / \mathrm{N}$ ratio to optimize wickability of fabric.

\begin{tabular}{|c|c|c|c|c|c|}
\hline Runs & Level & Flow rate $\left(\mathrm{Nm}^{3} / \mathbf{s}\right)$ & Pressure (Pa) & Power (W) & Time (min) \\
\hline Average & 1 & $35.72 *$ & 35.16 & 35.51 & 35.41 \\
\hline \multirow[t]{2}{*}{$S / N^{a}, \mathbf{d B}$} & 2 & 35.34 & $35.95 *$ & 35.49 & 35.52 \\
\hline & 3 & 35.48 & 35.43 & $35.53 *$ & $35.61 *$ \\
\hline Larger is & Delta & 0.38 & 0.79 & 0.05 & 0.20 \\
\hline better & Rank & 2 & 1 & 4 & 3 \\
\hline Average & 1 & 34.63 & $35.25 *$ & 34.75 & $34.88 *$ \\
\hline \multirow[t]{2}{*}{$\mathrm{S} / \mathrm{N}^{\mathrm{b}}, \mathrm{dB}$} & 2 & $34.95^{*}$ & 34.67 & 34.81 & 34.65 \\
\hline & 3 & 34.81 & 34.47 & $34.84 *$ & 34.86 \\
\hline Larger is & Delta & 0.31 & 0.78 & 0.09 & 0.23 \\
\hline better & Rank & 2 & 1 & 4 & 3 \\
\hline
\end{tabular}

*Optimum parameter level; a Wickability in warp direction; ${ }^{\text {b} W i c k a b i l i t y ~ i n ~ w e f t ~ d i r e c t i o n . ~}$

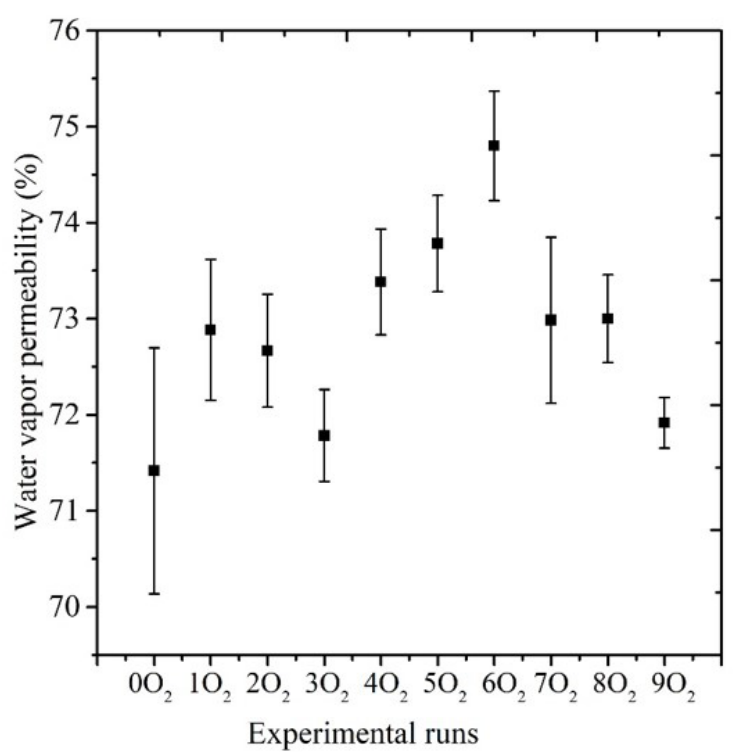

(a)

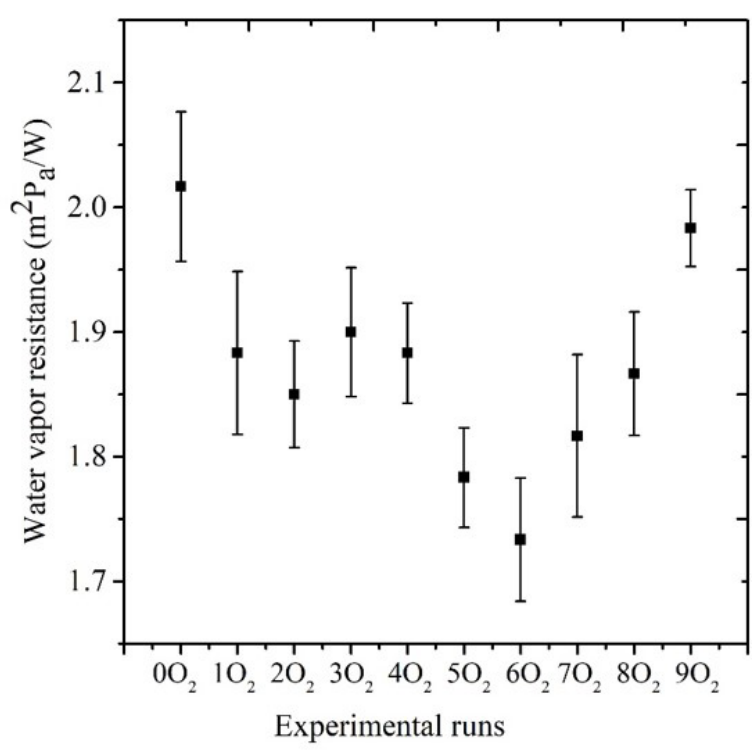

(b)

Figure 4. Oxygen plasma on water vapor permeability (a) and resistance (b) of fabric.

range of 1.73 to $1.98 \mathrm{~m}^{2} \mathrm{~Pa} / \mathrm{W}$ compared to $2.02 \mathrm{~m}^{2} \mathrm{~Pa} / \mathrm{W}$ of untreated blend fabric.

In fact, surface topography and pore structure of the fibre surfaces have a significant influence on water vapour transmission of the fabric. As a result of this influence, plasma-treated $\mathrm{P} / \mathrm{C}$ blend fabric had better comfort property by regulating water vapour that comes from the body than untreated fabric ${ }^{27,28}$. Moreover, better comfort property could be achieved by increasing water vapour permeability and decreasing the water vapour resistance through oxygen plasma treatment for tropical climatic conditions. Otherwise, moisture is trapped between the skin and clothing then, it leads to wet skin and discomfort ${ }^{8}$.

The optimum parameter levels and influential factors on water vapour permeability and water vapour resistance of plasma treated $\mathrm{P} / \mathrm{C}$ blend fabric are described in Table 3 . Here, similar methods and factors were used like that of wickability analysis. As displayed in Table 3, oxygen flow rate had the greatest effect on water vapour permeability and water vapour resistance of plasma treated fabric. With respect to the response table of $\mathrm{S} / \mathrm{N}$ ratio, the optimum parameter levels attained at $8.333 \times 10^{-7} \mathrm{Nm}^{3} / \mathrm{s}, 40 \mathrm{~Pa}, 600 \mathrm{~W}$ and $10 \mathrm{~min}$, by choosing "Larger is better", for water vapour permeability $\left(\mathrm{S} / \mathrm{N}^{\mathrm{a}}\right)$, while for water vapour resistance $(\mathrm{S} /$ $\mathrm{N}^{\mathrm{b}}$ ) it achieved that, by selecting "Smaller is better", at the levels of $1 \times 10^{-6} \mathrm{Nm}^{3} / \mathrm{s}, 50 \mathrm{~Pa}, 800 \mathrm{~W}$ and $20 \mathrm{~min}$. In warm conditions, releasing water vapour (body sweat) to the surrounding environment is necessary to maintain the body at a comfortable level. This is a reason for the selection of "Larger is better" and "Smaller is better" for water vapour permeability and water vapour resistance of plasma treated fabric, respectively.

\subsection{Thermal resistance and air permeability of fabric}

Figure 5 shows the thermal resistance and air permeability of plasma treated and untreated fabrics. According to the results, the plasma treated samples had lower insulation property compared to untreated 
Table 3. Response table for mean of $\mathrm{S} / \mathrm{N}$ ratio to optimize water vapour permeability $\left(\boldsymbol{S} / \boldsymbol{N}^{a}\right)$ and resistance $\left(\boldsymbol{S} / \boldsymbol{N}^{b}\right)$ of the fabric.

\begin{tabular}{|c|c|c|c|c|c|}
\hline Runs & Level & Flow rate $\left(\mathrm{Nm}^{3} / \mathrm{s}\right)$ & Pressure $(\mathrm{Pa})$ & Power (W) & Time (min) \\
\hline Average & 1 & 37.20 & 37.27 & $37.33^{*}$ & 37.25 \\
\hline \multirow[t]{2}{*}{$\mathrm{S} / \mathrm{N}^{\mathrm{a}}, \mathrm{dB}$} & 2 & $37.38^{*}$ & $37.28 *$ & 37.22 & $37.32 *$ \\
\hline & 3 & 37.22 & 37.24 & 37.24 & 37.23 \\
\hline Larger is & Delta & 0.18 & 0.04 & 0.11 & 0.09 \\
\hline better & Rank & 1 & 4 & 2 & 3 \\
\hline Average & 1 & -5.490 & -5.416 & -5.252 & -5.504 \\
\hline \multirow[t]{2}{*}{$\mathrm{S} / \mathrm{N}^{\mathrm{b}}, \mathrm{dB}$} & 2 & -5.113 & -5.276 & $-5.606^{*}$ & -5.121 \\
\hline & 3 & $-5.534^{*}$ & $-5.446^{*}$ & -5.280 & $-5.512 *$ \\
\hline Smaller is & Delta & 0.421 & 0.171 & 0.353 & 0.391 \\
\hline better & Rank & 1 & 4 & 3 & 2 \\
\hline
\end{tabular}

*Optimum parameter level; ${ }^{\mathrm{a}}$ water-vapour permeability; ${ }^{\mathrm{b}}$ water-vapour resistance.

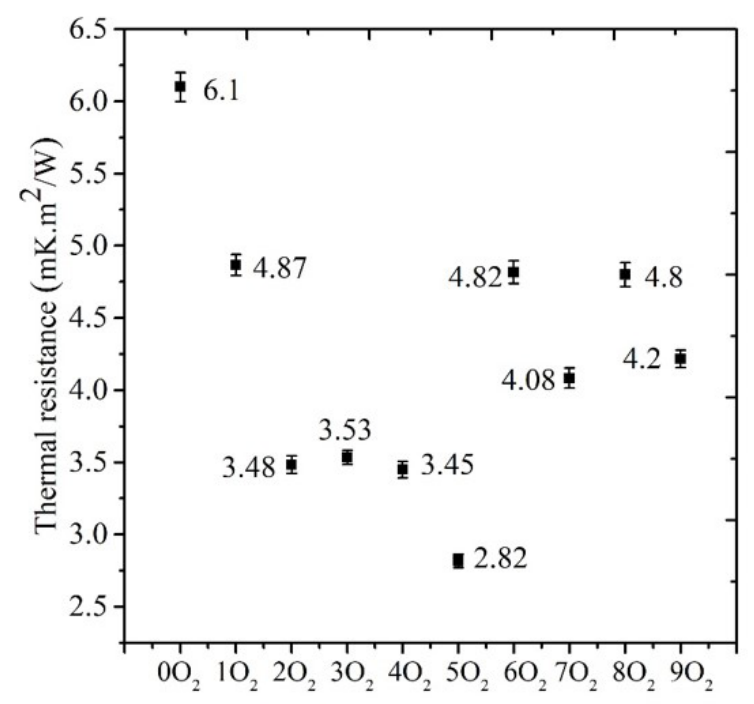

Experimental runs

(a)

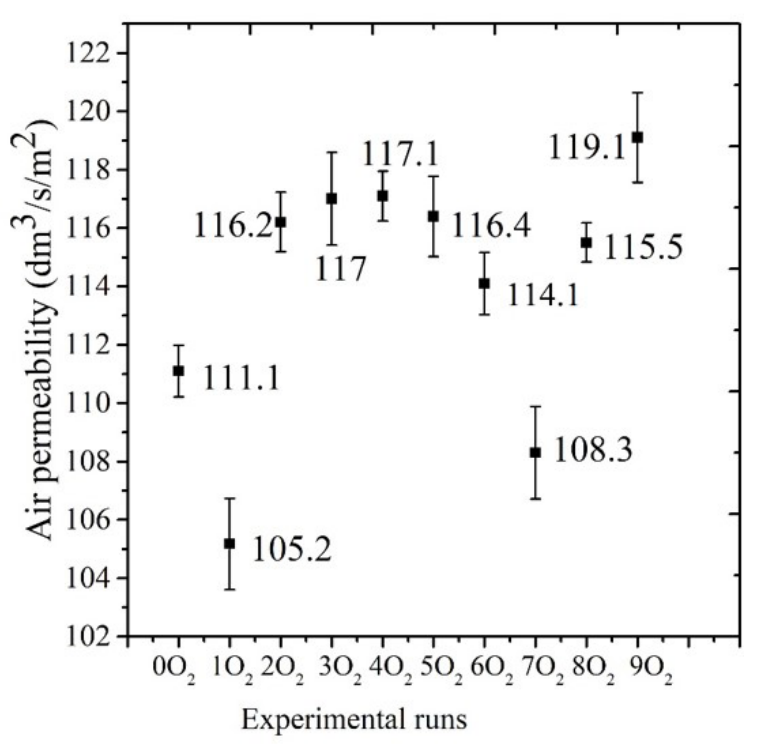

(b)

Figure 5. Effect of oxygen plasma on thermal resistance (a) and air permeability (b) of the fabric.

samples. Particularly, the thermal resistance decreased at least by $20.16 \%$. This may be due to the cleaning and activation effect of the plasma treatment. Since the effect of plasma is in nanometer depth onto the surface. That means, only the thin layer becomes more hydrophilic and adsorbs moisture mainly on the surface of polyester fibers. As a result, the thermal resistance of the fabric becomes decreased after plasma treatment. When the thermal resistance of clothing decreases in a hot climatic environment, the thermal energy is more easily dissipated and the body is cooled. Therefore, this type of treatment can be an option to change the thermal resistance of produced fabric and/or garment.

Regarding air permeability, two kinds of results were observed after plasma treatments. Specifically, the results revealed that the air permeability at experimental runs of $1 \mathrm{O}_{2}$ and $7 \mathrm{O}_{2}$ had lower than control samples, whereas others were higher than untreated samples. Many reasons may be taken into consideration to explain it. However, the surface roughness of cotton fiber plays a great role to determine the air permeability. When the degree of roughness increases, the air is trapped and cannot escape easily from the fabric ${ }^{25}$. On the other hand, air permeability of the fabric would improve when the degree of roughness decreased. Surprisingly, previous research works have also shown different outcomes regarding air permeability of cotton fabric ${ }^{32,33}$. In this study, the composition of $\mathrm{P} / \mathrm{C}$ blend fabric is $65 \%$ polyester and $35 \%$ cotton. Hence, surface modification depends on the amorphicity and crystallinity of each fibre. As can be shown in Figure 3c, the formation of more voids and cracks on the cotton fibre surface probably would lead to the reduction of air permeability of the blend fabric like experimental runs of $1 \mathrm{O}_{2}$ and $7 \mathrm{O}_{2}{ }^{24}$ However, the degree of roughness on the surface of polyester fiber is higher than the formation of voids. Probably, it facilitates the circulation of the air through the fabric rather than storing air in grooves like cotton ${ }^{34}$. Therefore, the overall air permeability of the blend fabric mainly depends on the surface modification of polyester and cotton fibres. 
Nevertheless, thermal resistance and air permeability of the blend fabric were governed by types of fibre, fabric construction and plasma conditions. The optimum parameters and influential variables of blend fabric thermal resistance and air permeability are indicated in Table 4 . As per the delta values, discharge power on thermal resistance and operating pressure on air permeability had the greatest effect in the oxygen plasma process. The optimum results of thermal resistance $\left(\mathrm{S} / \mathrm{N}^{\mathrm{a}}\right)$ scored at $1 \times 10^{-6} \mathrm{Nm}^{3} / \mathrm{s}, 50 \mathrm{~Pa}, 600 \mathrm{~W}$ and $10 \mathrm{~min}$ by selecting the "Smaller is better", whereas optimum outcomes of air permeability $\left(\mathrm{S} / \mathrm{N}^{\mathrm{b}}\right)$ found at $8.333 \times 10^{-7} \mathrm{Nm}^{3} / \mathrm{s}, 50 \mathrm{~Pa}, 700 \mathrm{~W}$ and $20 \mathrm{~min}$ by choosing the "Larger is better" during the analysis of the response with Taguchi method.

The results of One-way ANOVA for each thermal comfort property of oxygen plasma treated and untreated blend fabrics are summarized in Table 5. It clearly reveals that the means of experimental runs for each thermal comfort property is significantly different $(p<0.05)$ at $95 \%$ confidence level. Therefore, oxygen plasma treatment had a significant change on the comfort properties of $\mathrm{P} / \mathrm{C}$ blend fabric.

\subsection{Effect of aging on wettability of plasma treated fabric}

The effect of aging on wettability of air, argon and oxygen plasma treated and untreated $\mathrm{P} / \mathrm{C}$ blend fabric was performed by TEGWA drop test method. All treated, at the condition of $500 \mathrm{~W}, 30 \mathrm{~Pa}, 10 \mathrm{~min}$ and $1 \times 10^{-6} \mathrm{Nm}^{3} / \mathrm{s}$, and untreated samples were stored under standard condition for 1,7 and 14 day/s. The results of drop solution sink-in time and spread area are given in Figure 6. The dye solution on untreated fabric sunk-in within $28.6 \mathrm{sec}$, whereas for all treated samples, it was absorbed and disappeared in less than 10 seconds. After a 14 days aging period, the absorption time of plasma treated samples increased from 5.36 to $7.75 \mathrm{sec}$ for oxygen, 5.74 to $8.92 \mathrm{sec}$ for air and 6.36 to $9.72 \mathrm{sec}$ for argon plasma treatments as shown in Figure 6a. On the other hand, the spread area of the completely dried colour spot on untreated fabric was $1240 \mathrm{~mm}^{2}$. However, the spread area of plasma treated samples decreased from 1741 to $1570 \mathrm{~mm}^{2}$ for oxygen, 1684 to $1543 \mathrm{~mm}^{2}$ for air and 1610 to $1500 \mathrm{~mm}^{2}$ for argon plasma treatments as depicted in Figure 6b. Although

Table 4. Response table for mean of $\mathrm{S} / \mathrm{N}$ ratio to optimize thermal resistance and air permeability of the fabric.

\begin{tabular}{lccccc}
\hline \multicolumn{1}{c}{ Runs } & Level & Flow rate $\left(\mathbf{N m}^{3} \mathbf{s}\right)$ & Pressure (Pa) & Power $(\mathbf{W})$ & Time $(\mathbf{m i n})$ \\
\hline Average & 1 & -11.85 & -12.25 & $-13.68^{*}$ & -11.75 \\
\hline $\mathbf{S} / \mathbf{N}^{\mathbf{a}}, \mathbf{d B}$ & 2 & -11.14 & -11.16 & -11.37 & $-12.24^{*}$ \\
\hline & 3 & $-12.79^{*}$ & $-12.38^{*}$ & -10.73 & -11.79 \\
\hline Smaller is & Delta & 1.65 & 1.22 & 2.95 & 0.49 \\
\hline better & Rank & 2 & 3 & 1 & 4 \\
\hline Average & 1 & 41.02 & 40.82 & 40.93 & 41.08 \\
\hline S/N $\mathbf{b}, \mathbf{d B}$ & 2 & $41.28^{*}$ & 41.29 & $41.39^{*}$ & 41.03 \\
\hline & 3 & 41.14 & $41.33^{*}$ & 41.11 & $41.32^{*}$ \\
\hline Larger is & Delta & 0.26 & 0.51 & 0.45 & 0.29 \\
\hline better & Rank & 4 & 1 & 2 & 3
\end{tabular}

*Optimum parameter level; athermal resistance; ${ }^{\text {bair }}$ permeability.

Table 5. One-way ANOVA on thermal comfort properties of the $\mathrm{P} / \mathrm{C}$ blend fabric.

\begin{tabular}{|c|c|c|c|c|c|}
\hline Source of variation & DF & Sum of Squares & Mean Square & F-Value & Prob $>$ F \\
\hline Between groups & 9 & 1247.87 & 138.65 & 19.26 & $5.44 \mathrm{E}-8^{\mathrm{a}}$ \\
\hline Within groups & 20 & 144 & 7.2 & & \\
\hline Total & 29 & 1391.87 & & & \\
\hline Between groups & 9 & 966.83 & 107.43 & 21.78 & $1.87 \mathrm{E}-8^{\mathrm{b}}$ \\
\hline Within groups & 20 & 98.67 & 4.93 & & \\
\hline Total & 29 & 1065.5 & & & \\
\hline Between groups & 9 & 54.57 & 6.06 & 2.17 & $0.04^{\mathrm{c}}$ \\
\hline Within groups & 50 & 139.69 & 2.79 & & \\
\hline Total & 59 & 194.26 & & & \\
\hline Between groups & 9 & 0.39 & 0.04 & 2.81 & $0.01^{\mathrm{d}}$ \\
\hline Within groups & 50 & 0.77 & 0.02 & & \\
\hline Total & 59 & 1.16 & & & \\
\hline Between groups & 9 & 49.44 & 5.49 & 190.30 & $0^{\mathrm{e}}$ \\
\hline Within groups & 50 & 1.44 & 0.03 & & \\
\hline Total & 59 & 50.88 & & & \\
\hline Between groups & 9 & 1763.49 & 195.94 & 12.35 & $1.60 \mathrm{E}-12^{\mathrm{f}}$ \\
\hline Within groups & 90 & 1428.20 & 15.87 & & \\
\hline Total & 99 & 3191.69 & & & \\
\hline
\end{tabular}

${ }^{a}$ Wickability in warp direction; ${ }^{b}$ Wickability in weft direction; ${ }^{c}$ water vapour permeability; ${ }^{\mathrm{d}}$ water vapour resistance; ${ }^{\mathrm{e}}$ thermal resistance; ${ }^{\mathrm{f}}$ air permeability. 


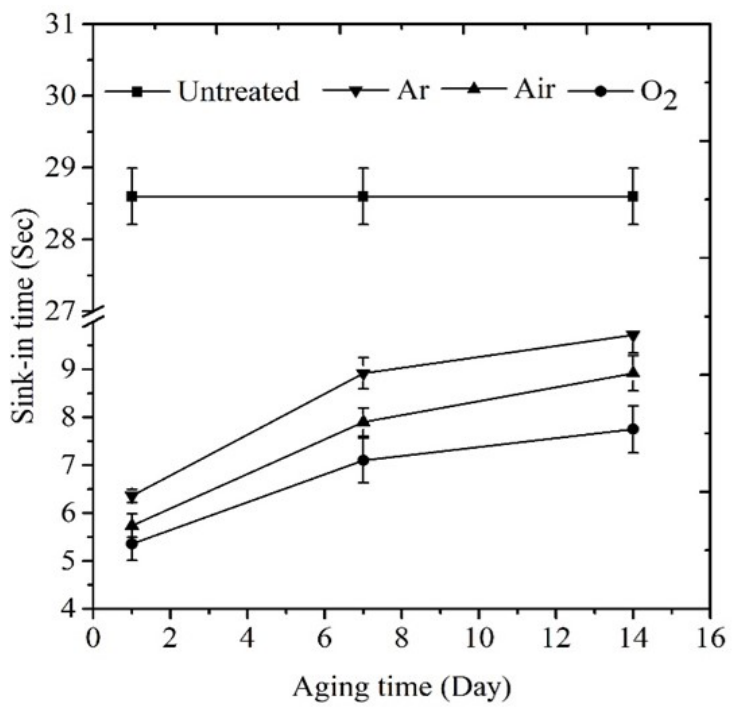

(a)

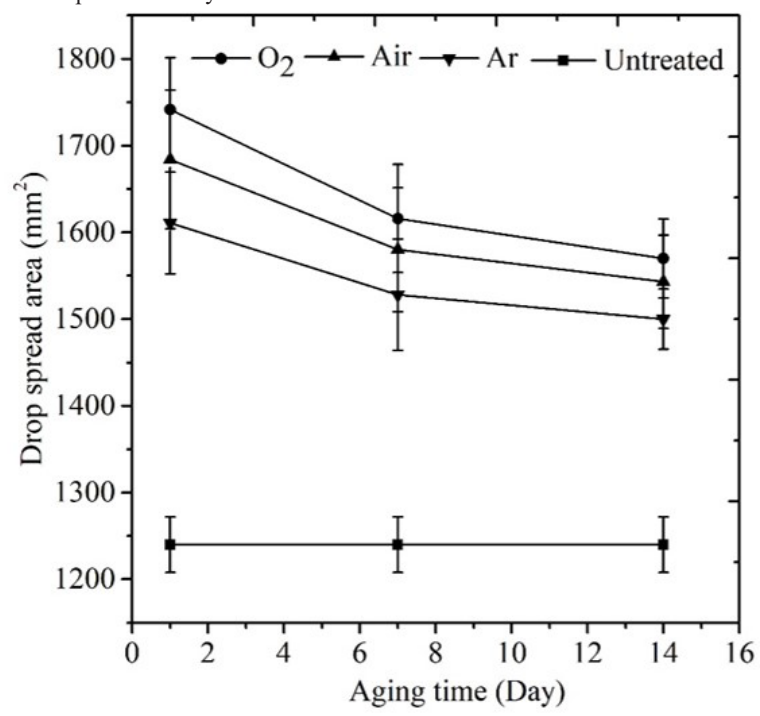

(b)

Figure 6. Evaluation of aging effect on plasma treated fabric by sink-in time (a) and drop spread area (b).

all treated samples had a much better hydrophilic behaviour, oxygen plasma was more effective compared to air and argon plasma treatments. This can be explained by the formation of more polar groups for instance, hydroxyl and carboxylic on the blend fabric surfaces ${ }^{35}$.

As it is shown clearly in Figure 6, the rate of aging sharply increased in the first 7 days, whereas it slowly decreased for the last 7 days. This indicates that the stability of active species generated on the blend fabric significantly depends on the aging time ${ }^{36}$. Nevertheless, the wettability of plasma treated fabric was better than untreated fabric even after two weeks. Similarly, after 14 days, the spread area of plasma treated samples were smaller compared to freshly treated fabrics, which revealed that the hydrophilicity of the treated fabrics reduces after longer storage times. When the treated $\mathrm{P} / \mathrm{C}$ blend fabrics were placed in standard condition for some days, the surface energy decreased due to the reorientation of the polar groups in the bulk matter and migration of low molecular weight segments to the surface ${ }^{35}$.

\subsection{Surface characterization}

SEM images of plasma treated and untreated blend fabrics are shown above in Figure 3. The individual fibres were scanned at the size of $1 \mu \mathrm{m}$ and magnification of $10,000 \mathrm{X}$ with $5 \mathrm{kV}$ to analyze the surface morphology. It can be seen that after argon, oxygen and air plasma treatment for 10 minute, the etching took place and developed roughness, cracks and grooves on the surface of polyester and cotton fibres compared to untreated fibres. That means, untreated fibres (Figure $3 \mathrm{a}$ ), in the $\mathrm{P} / \mathrm{C}$ blend fabrics, have comparatively smooth and flat surfaces.

Plasma bombardment with high energetic particles such as UV photons modified the surface morphologies of the fibers. Specifically, argon plasma (Figure 3b) formed cracks, channels and roughness on cotton fibres, and etched and rough surface of polyester fibres ${ }^{37}$. However, oxygen plasma (Figure 3c) produced a high degree of roughness and a number of void spaces on cotton fibres, as well as solidified nanospots on the surface of polyester fibres compared to argon plasma. In addition, air plasma (Figure 3d) also developed

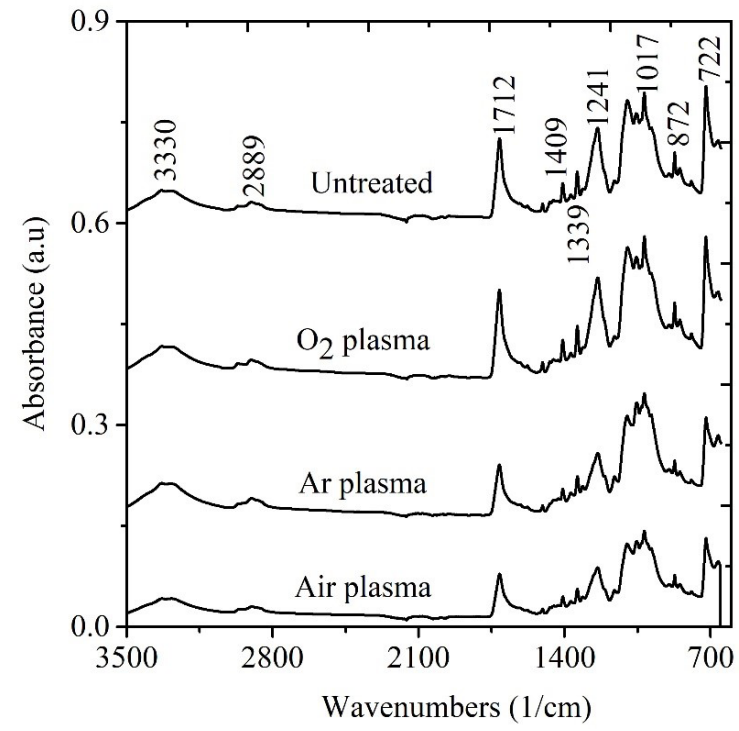

Figure 7. ATR-FTIR spectra of plasma treated and untreated P/C blend fabrics.

similar topography to that of oxygen plasma treatment, but the influence of air plasma is more pronounced compared to oxygen plasma treatment ${ }^{38}$. In all plasma treated samples, some solidified nano-spots are formed on the surface of polyester fibre ${ }^{39}$. These confirmed that plasma treatments have a potential to change the surface of $\mathrm{P} / \mathrm{C}$ blend fabric.

The ATR-FTIR spectra of untreated, oxygen, argon and air plasma-treated $\mathrm{P} / \mathrm{C}$ blend fabric at the condition of $500 \mathrm{~W}$, $30 \mathrm{~Pa}, 10 \mathrm{~min}$ and $1 \times 10^{-6} \mathrm{Nm}^{3} / \mathrm{s}$ are presented in Figure 7. Due to $65 \%$ of polyester fiber, the emerging peaks on the surface of blend fabric are similar to the peaks of $100 \%$ polyester fabric ${ }^{2,40}$. In particular, the developed peaks at $1712,1409,1241,1017$ and $722(872) \mathrm{cm}^{-1}$ can be assigned to the chemical nature of polyester and corresponding to the functional groups of carboxylic $(\mathrm{C}=\mathrm{O})$, aromatic ring, carboxylic $(\mathrm{C}-\mathrm{O})$, ester $(\mathrm{O}=\mathrm{C}-\mathrm{O}-\mathrm{C})$ and aromatic $(\mathrm{C}-\mathrm{H})$, 
Table 6. The absorbance ratio on $\mathrm{P} / \mathrm{C}$ blend fabric surface

\begin{tabular}{ccc}
\hline Sample & $\mathbf{A}_{\mathbf{1 2 4 1}} / \mathbf{A}_{\mathbf{7 2 2}}$ & $\mathbf{A}_{\mathbf{1 7 1 2}} / \mathbf{A}_{\mathbf{7 2 2}}$ \\
\hline Untreated P/C & 0.623 & 0.547 \\
\hline Ar-plasma treated & 0.589 & 0.448 \\
\hline $\mathrm{O}_{2}$-plasma treated & 0.659 & 0.599 \\
\hline Air-plasma treated & 0.736 & 0.656 \\
\hline
\end{tabular}

respectively ${ }^{41}$. On the other hand, peaks observed at 3330 , 2889 and $1339 \mathrm{~cm}^{-1}$ would be associated with the chemical groups of hydroxyl $(\mathrm{O}-\mathrm{H})$, aliphatic $(\mathrm{C}-\mathrm{H})$ and alkane $\left(\mathrm{CH}_{2}\right)$ in the cotton fiber, correspondingly ${ }^{41,42}$. As seen in Figure 7 , the spectra of plasma treated and untreated samples are similar. It does not show remarkable difference on the surface chemistry of the blend fabric ${ }^{24}$.

However, the absorbance ratio revealed some intensity differences among untreated, oxygen, argon and air plasmatreated samples as depicted in Table 6 . It was calculated by taking $722 \mathrm{~cm}^{-1}$ in order to normalize 1712 and $1241 \mathrm{~cm}^{-1}$ peaks. According to the intensity ratio, argon plasma treated spectra is less than untreated and other plasma treated samples. On the other hand, the absorbance ratio of oxygen and air plasma treatments are higher than that of control sample. Most likely, this shows the formation of more polar groups on the surface of blend fabric due to those plasma treatments ${ }^{4,43}$. As a result, all plasma treated blend fabric is more hydrophilic than the untreated fabric. Peak intensity at $722 \mathrm{~cm}^{-1}$ for aromatic $\mathrm{C}-\mathrm{H}$ out of plane vibrations was used for normalization.

Generally, the absorbance ratio of ATR-FTIR peaks does not indicate a significance difference among the samples. In fact, plasma treatment only modifies the uppermost surface of a textile material in the depth of a few nanometers. However, the ATR-FTIR analysis is not appropriate to detect a very thin layer and percentage of elemental analysis. In order to resolve this limitation, more sophisticated analytical techniques are needed to analyze the surface chemistry of plasma treated textile materials ${ }^{2,44}$.

\section{Conclusions}

In this paper, the influence of plasma surface modification on thermal comfort properties of $\mathrm{P} / \mathrm{C}$ blend fabric was illustrated and discussed. The non-thermal plasma treatment was conducted on the samples of $65 \%$ polyester and $35 \%$ cotton blend fabric using argon, oxygen and air as working gases. In particular, optimization of the vacuum oxygen plasma process was designed and analyzed by the Taguchi method. After oxygen plasma treatment, the blend fabric thermal comfort properties were remarkably improved. The results revealed that wickability of treated fabrics increased in the range of 43.25 to $60.75 \%$ and 37.63 to $57.89 \%$ compared to untreated fabric in the warp and weft directions, respectively. On the other hand, the relative water vapour permeability $\mathrm{P}_{\mathrm{wv}}(\%)$ improved 71.8 to $74.8 \%$ after treatment. In addition, water vapour resistance of plasma treated fabric reduced in the range of 1.73 to $1.98 \mathrm{~m}^{2} \mathrm{~Pa} / \mathrm{W}$ compared to $2.02 \mathrm{~m}^{2} \mathrm{~Pa} / \mathrm{W}$ of control sample. The thermal resistance also decreased at least by $20.16 \%$, whereas regarding air permeability, two kinds of results were observed. At the experimental runs of
$1 \mathrm{O}_{2}$ and $7 \mathrm{O}_{2}$, their results were reduced, while in the other experimental runs enhanced. Probably, the reasons may be related to the blend ratio of the fiber in the blend fabric. The surface morphology of plasma treated and untreated blend fabric depends on the amorphicity and crystallinity of each fibre as the SEM images confirmed.

\section{Acknowledgments}

This work has been fully supported by the Engineering Education Capacity Building Program of Ethiopia (EECBP), German Academic Exchange Service (DAAD) and Dire Dawa University. Authors are very grateful to thank Ziad Heilani and Paul-Gerhard Ringwald (Albstadt-Sigmaringen University) for their support during laboratory works.

\section{References}

1. Sarker F, Prasad RK, Howlader MR, Abir NAR. Scope of dyeing Polyester Cotton (PC) blended fabric in single bath process for water, energy and time saving. IOSR J. Polymer. Text. Eng. 2015;2(3):12-6.

2. Kale K, Palaskar S, Hauser PJEA. Atmospheric pressure glow discharge of helium-oxygen plasma treatment on polyester/cotton blended fabric. Indian J Fibre Text Res. 2011;36(June):137-44.

3. Zou Y, Reddy N, Yang Y. Reusing polyester/cotton blend fabrics for composites. Compos, Part B Eng. 2011;42(4):763-70.

4. Kan CKLC. Atmospheric pressure plasma treatment for grey cotton knitted fabric. Polymers (Basel). 2018;10(53):1-16.

5. Ibrahim NA, Eid BM, Youssef MA, Ameen HA, Salah AM. Surface modification and smart functionalization of polyestercontaining fabrics. J Ind Text. 2013;42(4):353-75.

6. Prasad RK, Shahid ADM. A comparative study between one bath dyeing method for Polyester Cotton (PC) blended fabric over conventional two bath dyeing method. Eur Sci J. 2015;11(33):270-80.

7. Onofrei E, Rocha AM, Catarino A. The influence of knitted fabrics' structure on the thermal and moisture management properties. J Eng Fibers Fabrics. 2011;6(4):10-22.

8. Kothari VK. Thermo-physiological comfort characteristics and blended yarn woven fabrics. Indian J Fibre Text Res. 2006;31:177-86.

9. Özdemir H. Thermal comfort properties of clothing fabrics woven with polyester/cotton blend yarns. AUTEX Res J. 2017;17(2):135-41.

10. El Messiry M, El Ouffy A, Issa M. Microcellulose particles for surface modification to enhance moisture management properties of polyester, and polyester/cotton blend fabrics. Alex Eng J. 2015;54(2):127-40.

11. Yuan J, Zhang Z, Yang M, Guo F, Men X, Liu W. Surface modification of hybrid-fabric composites with amino silane and polydopamine for enhanced mechanical and tribological behaviors. Tribol Int. 2017;107:10-7.

12. Kamel MM, Allam OG, El Gabry LK. Surface modification methods for improving dyeability of acrylic fabric using natural biopolymer. J Appl Sci Res. 2013;9(6):3520-9. 
13. Li G, Liu H, Li T, Wang J. Surface modification and functionalization of silk fibroin fibers/fabric toward high performance applications. Mater Sci Eng C. 2012;32(December):627-36.

14. Goddard JM, Hotchkiss JH. Polymer surface modification for the attachment of bioactive compounds. Prog Polym Sci. 2007;32(April):698-725.

15. Kumar PS, Gunasundari E. Sustainable Wet Processing-An Alternative Source for Detoxifying Supply Chain in Textiles. In: Muthu SS, editor. Textile Science and Clothing Technology. Singapore: Springer; 2018. p. 37-60.

16. Jelil RA. A review of low-temperature plasma treatment of textile materials. J Mater Sci. 2015;(June):1-31.

17. Yilma BB, Luebben JF, Nalankilli G. Cold plasma treatment in wet chemical textile processing. Fibres Text East Eur. 2020;28(6):118-26.

18. Inagaki N. Plasma surface modification and plasma polymerization. Plasma surface modification and plasma polymerization. Lancaster, PA: Technomic; 1996.

19. Kalia S, Thakur K, Celli A, Kiechel MA, Schauer CL. Surface modification of plant fibers using environment friendly methods for their application in polymer composites, textile industry and antimicrobial activities: A review. J Environ Chem Eng. 2013;1:97-112.

20. Sun D. Surface Modification of Natural Fibers Using Plasma Treatment. In: Kalia S, editor. Biodegradable Green Composites. Hoboken: John Wiley \& Sons; 2016. p. 18-39.

21. Yaman N, Özdogan E, Seventekin N. Improving physical properties of polyamide fibers by using atmospheric plasma treatments. Tekstil ve Konfeksiyon. 2012;22(2):102-5.

22. Ferri A, Rombaldoni F, Mazzuchetti G, Rovero G, Sicardi S. Thermal properties of wool fabrics treated in atmospheric pressure post-discharge plasma equipment. J Eng Fibers Fabrics. 2012;7(3):75-81.

23. Karaca B, Demir A, Özdoğan E, Işmal Ö. Environmentally benign alternatives: plasma and enzymes to improve moisture management properties of knitted PET fabrics. Fibers Polym. 2010;11(7):1003-9.

24. Senthilkumar P, Karthik T. Effect of argon plasma treatment variables on wettability and antibacterial properties of polyester fabrics. J. Inst. Eng. India Ser. E. 2016;97(1):19-29.

25. Prakash C, Ramakrishnan G, Chinnadurai S, Vignesh S, Senthilkumar M. Effect of plasma treatment on air and watervapor permeability of bamboo knitted fabric. Int J Thermophys. 2013;34(October):2173-82.

26. Rajwin AJ, Prakash C. Effect of air plasma treatment on thermal comfort properties of woven fabric. Int J Thermophys. 2017;38(11)

27. Jebastin Rajwin A, Prakash C. A study on the effect of plasma treatment on thermal comfort properties of cotton fabric. J Test Eval. 2018;(April):1-10.

28. Jebastin Rajwin A, Prakash C. Effect of modified yarn path ring spinning on thermal comfort properties of cotton fabrics after plasma treatment. J Nat Fibers. 2019;18:1-12.
29. Legerská J, Lizák P. Evaluation of the specific physiological properties for the selected assortment of work clothes. Procedia Eng. 2016;136:227-32.

30. Hes L, Araujo M. Simulation of the effect of air gaps between the skin and a wet fabric on resulting cooling flow. Text Res J. 2010;80(14):1488-97.

31. Amitava M. The Taguchi method. Wiley Interdiscip Rev Comput Stat. 2011;3:472-80.

32. Karahan H, Özdoğan E, Demir A, Ayhan H, Seventekin N. Effects of atmospheric pressure plasma treatments on certain properties of cotton fabrics. Fibres Text East Eur. 2009;17(2):19-22.

33. Prabha R, Vasugi N. Evaluating the comfort properties of plasma treated and plasma untreated cotton fabrics finished with plant extracts. Int J Innov Res Sci Eng Technol. 2016;5(11):20061-6.

34. Ramakrishnan G, Prakash C, Janani G. Effect of environmentally friendly plasma treatment on microfibre fabrics to improve some comfort properties. Int J Cloth Sci Technol. 2018;30(1):2937.

35. Kan C, Lam Y. The effect of plasma treatment on water absorption properties of silk fabrics. Fibers Polym. 2015;16(8):1705-14.

36. Malek RMA, Holme I. The effect of plasma treatment on some properties of cotton. Iran Polym J. 2003;12(4):271-80.

37. Wang CX, Lv JC, Ren Y, Zhi T, Chen JY, Zhou QQ, et al. Surface modification of polyester fabric with plasma pretreatment and carbon nanotube coating for antistatic property improvement. Appl Surf Sci. 2015;359:196-203.

38. Rani KV, Sarma B, Sarma A. Plasma treatment on cotton fabrics to enhance the adhesion of Reduced Graphene Oxide for electro-conductive properties. Diamond Related Materials. 2018;84:77-85.

39. Chongqi M, Shulin Z, Gu H. Anti-static charge character of the plasma treated polyester filter fabric. J Electrost. 2010;68(2):1115 .

40. Gore AV, Venkataraman A. Identification of polyester/cellulosic blends using FT-IR spectrometer. Indian J Fibre Text Res. 1998;23(3):165-9.

41. Lima da Silva RC, Alves C Jr, Nascimento JH, Neves JRO, Teixeira V. Surface modification of polyester fabric by nonthermal plasma treatment. J Phys Conf Ser. 2012;406(1)

42. Platnieks, O.; Gaidukovs, S.; Barkane, A.; Gaidukova, G.; Grase, L.; Thakur, V. K.; Filipova, I.; Fridrihsone, V.; Skute, M.; Laka M. Highly loaded cellulose / Poly (butylene succinate) sustainable composites for woody-like advanced. Molecules. 2020;25(121):1-18.

43. Caschera D, Mezzi A, Cerri L, Caro TD, Riccucci C, Ingo $\mathrm{GM}$, et al. Effects of plasma treatments for improving extreme wettability behavior of cotton fabrics. Cellulose. 2014;21(1):74156.

44. Samanta KK, Jassal M, Agrawal AK. Antistatic effect of atmospheric pressure glow discharge cold plasma treatment on textile substrates. Fibers Polym. 2010;11:431-7. 